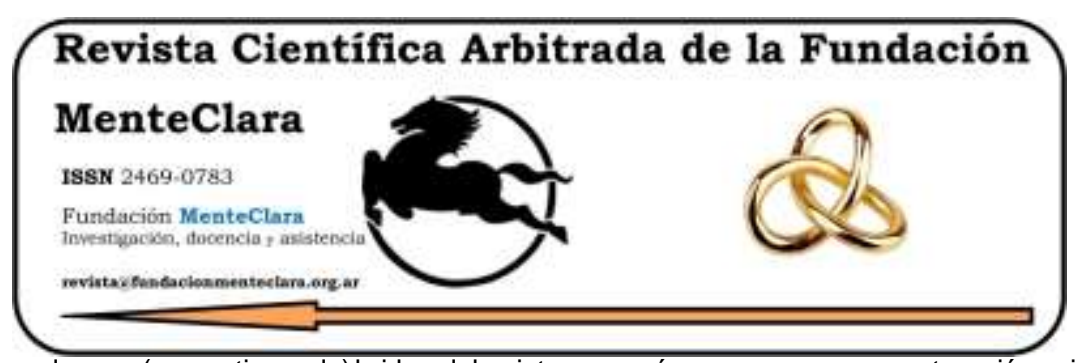

Artículos atravesados por (o cuestionando) la idea del sujeto -y su género- como una construcción psicobiológica de la cultura. Articles driven by (or questioning) the idea of the subject -and their gender- as a cultural psychobiological construction.

Vol. 5 (2020), enero-diciembre ISSN 2469-0783

https: / / datahub.io/dataset/2020-5-e152

\title{
LA CONJUNCIÓN FRONTERIZA DEL OTRO
}

\author{
THE FRONTIER CONJUNCTION OF THE OTHER \\ Milton Aragón ${ }^{1}$, Francisco José Francisco Carrera ${ }^{2}$
}

Cómo citar este artículo / Citation: Aragón M. \& Francisco Carrera F. J. (2020). «La conjunción fronteriza del Otro". Revista Científica Arbitrada de la Fundación MenteClara, Vol. 5 (152). DOI: https://doi.org/10.32351/rca.v5.152

Copyright: (c) 2020 RCAFMC. Este artículo de acceso abierto es distribuido bajo los términos de la licencia Creative Commons Attribution 4.0 International License (CC BY 4.0). Recibido: 05/05/2020. Aceptado: 12/05/2020 Publicación online: 13/05/2020

Conflicto de intereses: Ninguno que declarar.

\section{Resumen}

Se aborda la experiencia del Otro en espacios de frontera que marcan el límite entre los mismos y los otros, por medio de un aquí y un allá. Espacios simbólicos que generan encuentros y desencuentros en distintos niveles. Pero pueden volverse espacios de conjunción que pueden permitir la convergencia de los Otros por medio de la solidaridad y el reconocimiento del otro.

\begin{abstract}
The experience of the Other is addressed in frontier spaces that mark the limit between the same and the others, through a here and there. Symbolic spaces that generate encounters and disagreements in different levels. But they become spaces of conjunction that allow the convergence of the Others, through solidarity and recognition of the other.
\end{abstract}

Palabras Claves: Otredad; Espacio; Frontera; Solidaridad

Keyw ords: Otherness; Space; Border; Solidarity

\footnotetext{
${ }^{1}$ Universidad Autónoma de Coahuila / CONACYT / Academia Mexicana de Ciencias, México. miltonaragon@uadec.edu.mx

2 Universidad de Valladolid, España. franciscojose.francisco@uva.es
} 


\section{Introducción}

La frontera es definida por la Real Academia de la Lengua Española como: "Puesto y colocado enfrente"; "Confin de un Estado". Definiciones que dotan al espacio de un sentido de marcar un aquí frente a un allá. El limite produce una división del espacio y construye lugares que se excluyen. Un adentro y un afuera. Ser nacional o extranjero. Lugareño o extranjero. De ahí que la frontera opera como un símbolo de doble entrada, una que aglutina otra que excluye. Genera una paradoja de la totalidad en los fragmentos. La frontera se vuelve un elemento estructurador de la identidad del grupo del aquí. Emerge una unidad dual desde donde se simboliza al Otro como aquel-que-no-es-de-aquí. Por ello uno no puede dejar de ver el tremendo potencial de la frontera como lugar de lo posible, pues en su sentido liminar, la frontera ofrece riqueza en matices y pluralidad de contornos pues es zona creativa por antonomasia. Está en perfecta autocontrucción, en constante crecimiento de manera retroprogresiva a la manera de Pániker (2001, 2006 y 2016).

Como la función deíctica de los palillos en la cultura japonesa que con acierto nos ha mostrado Barthes (2014), hay cierto grado de señalización en la idea de frontera, recoge, aparta y unifica, pero ante todo dice "aquî" de forma enfática, para no dar lugar a dudas de que es una frontera, el problema es olvidar que a pesar de esto la frontera es marca creada y como tal hace que lo que está delante y lo que está detrás no se "confundan" a la vez que abre una línea de unión y pulsión hibrida que facilita la comunión entre las partes que están a uno u otro lado. Por eso la visión que recoge este texto se fundamenta analógicamente, de forma cuidadosa y prudente, pues ha de mediar entre la pulsión hacia lo univoco y lo plurivoco manifestado para entender mejor los procesos, las 
vidas y los contornos de juego de espejos que nos recuerdan el camino hacia una, repito, comunicante, en tanto que común, realidad.

Ante esto surge la interrogante: ¿Cómo la frontera al ser un lugar de conjunción construye la representación de un sujeto anónimo que temporalmente se encuentra aquí pero su lugar es allá? La intención no es dar una respuesta univoca a esta pregunta, sino el objetivo es llevar a cabo una reflexión que vaya de la experiencia del Otro y los Mismos a la solidaridad como forma de devolverle el rostro al Otro.

\section{La frontera como simbolo}

Martin Buber (1998) nos mostró, desde la perspectiva dialógica, que el yo y el tú se reconfiguran en un alter-mundo. Se configura entonces un tercer entorno en el que las subjetividades se diluyen en un entre-mundo en el que sólo se puede sobrevivir a través de la analogía y del diálogo. En caso contrario uno debe emigrar, de nuevo, de este mundo del entre hacia su lugar de origen. De tal forma que la frontera es un espacio simbólico de encuentros y desencuentros entre los Mismos y los Otros.

Para los Mismos la frontera es un símbolo que los cohesiona. Desde donde se construyen sus códigos, por lo tanto, todo aquello que no forma parte de ellos se significa como una amenaza, pues los ídolos: "[...] son proyecciones del hombre, de su yo, de su narcisismo. El idolo es sólo uno en realidad: el Yo, el gran Narciso, con un sinnúmero de rostros $y$ manifestaciones diferentes. Pero en el fondo es el mismo: el narcisismo" (Beuchot, 2004 ${ }^{\mathrm{a}}$. Es el gran Narciso que los construye como mismos, como fraternos, como parte de la Totalidad que opera en ese espacio y tiempo. El aquí frente allá. El nosotros frente aquellos. La razón frente a lo desquiciado. El orden frente al desorden. Lo univoco de la pertenencia a ese Yo del cual emerge la identidad de los-que-son-de-aquí. 
La frontera como ícono se construye en los-que-no-son-aquí. Su función es de esperanza, sueños, utopías, idealización simbólica de un lugar equivoco para florecer, porque el ícono "No permite el egoísmo o narcisismo que nos hace quedarnos en nosotros mismos [...] sino que nos hace polarizarnos hacia el otro [...] Con lo cual cumple excelentemente la condición de simbolo [que es] pasar algo superior desde lo inferior, a lo universal desde lo particular, a lo espiritual desde lo material" (Beuchot, $\left.2004^{a}\right)$.

La frontera como símbolo-ícono se vuelve el lugar de convergencia de lo múltiple frente a lo mismo. De lo abierto a lo cerrado. De la suma de la partes de la Totalidad. De lo fragmentos de lo segregado. Es el lugar que permite la mediación analógica, puesto que la analogía "no es identidad. No es semejanza completa y plena. En ella predomina la diversidad. Pone limites" (Beuchot, 2004a). El límite analógico permitiría comprender el Otro desde lo Mismo, no es ponerse en su lugar, sino desde el-ser-deaquí interpretar el-ser-de-allá, por lo tanto tender un puente entre el nosotros y ellos, por ende devolverle el rostro.

Pero hay tener cuidado de no caer en la trampa de la generalización, pues no sólo existe un tipo de frontera, éstas varian según su escala y simbolización. En la microescala la frontera se delimita desde el cuerpo, por lo tanto es móvil. Corresponde a la experiencia espacial del sujeto en sus trayectos cotidianos. En la macroescala la frontera se materializa en los muros que dividen algunos países o en las garitas de vigilancia fronteriza. Los Estado-Nación marcan un límite claro de sus territorios. Se construye un Otro general, que se define en función de la frontera nacional. La mesoescala sería la frontera delimitada por la comunidad, los comunes. Ésta puede ser materializada como en el caso fraccionamientos cerrados en las ciudades, o simbólica, como los grupos identitarios regionales, que pueden ser: clase social, casta, lengua, raza 
o ubicación geográfica. Aquí se construyen los otros específicos: el pobre, el migrante, el loco, los cuales están vinculados a la experiencia del Otro. Es el espacio de la fraternidad, aunque también puede transformarse en un lugar para la solidaridad.

Aquí queda manifestada esa potencialidad absoluta de la frontera como espacio propio de lo liminar en concreta actualización mutante, es espacio de lo movible, espacio híbrido y mestizo, acaso la única tierra vacía trayendo a colación el concepto latino de Terra Nullis, que hacía referencia a aquellos territorios que no presentan una soberanía factual y que por tanto son susceptibles de ser utilizados para crear una nueva nación. Así se antoja la frontera, como espacio posible, fijo y a la vez en constante estado mutacional por el fluyo y reflujo de poblaciones, ideas y realidades. Es un espacio concreto pero que subsiste más allá de su realidad fisica y en esto se abre potencialmente a cualquier realidad a punto de ser manifestada gracias al intercambio y la comunión pero también al conflicto y la tensión. Asimismo está abierta a la llegada de las voluntades creativas que puedan reclamar santuario, santuario que dé espacio a la vieja identidad que se relaciona con lo nuevo y así se interfecunda con lo Otro que empieza a ser parte del Uno.

\section{La experiencia del Otro}

En el prólogo de Identidad y violencia, Amartya Sen, cuenta una anécdota ocurrida en un aeropuerto. La cual es un buen ejemplo de la experienciadel Otro. Que se puede definir como aquel momento en el que el rostro es borrado y se forma parte de ese Otro que no pertenece a los Mismos, pues explica:

"Hace unos años, cuando regresaba a Inglaterra después de un corto viaje (en ese entonces era director del Trinity College de 
Cambridge), el oficial de migraciones del aeropuerto de Heathrow, quien controló mi pasaporte indio con bastante rigor, me planteó una pregunta filosófica de cierta complejidad. Tras ver la dirección de mi casa en el formulario de migraciones (Residencia del Director, Trinity College, Cambridge), me preguntó si el director, de cuya hospitalidad evidentemente yo gozaba, era un amigo cercano. Me demoré unos segundos, porque no me quedaba del todo claro si podía afirmar ser mi propio a migo. [...] Debido a que me demoré en dilucidar todo esto, el oficial de migraciones quiso saber exactamente por qué había dudadoy, en particular, si habia alguna irregularidad para mi regreso en Gran Bretaña.” (Sen, 2008)

El incidente de Sen no pasó a mayores, salvo volverse una anécdota, pero dicho acontecimiento lo llevo a reflexionar que:

"la identidad puede ser un asunto complicado [porque] Cuando dejamos de prestar atención a la noción de ser idéntico a sí mismo y la centramos en compartir una identidad con otros miembros de un grupo particular (que es la forma que muchas veces adopta la idea de identidad social), la complejidad aumenta aún más" (Sen, 2008).

De tal forma, que muchos problemas sociales y politicos giran en torno a los opuestos. La cuestión es de peso a estas alturas y en nuestro mundo altermoderno e híper tecnificado y aparentemente globalizado. Compartir una identidad en cierto sentido diluye esa identidad, pero asimismo la refuerza, pero también "Se degrada lo que es común a nuestra humanidad cuando las múltiples divisiones del mundo se unifican en un sistema de clasificación supuestamente dominante: en términos de religión, comunidad, cultura, nación o civilización" (Sen, 2008). Creándose vínculos que unen y dan firmeza, pero a la vez diluye y fragiliza la 
experiencia del uno al abrirse al otro y entrar en comunión. Ya sea por el recuerdo de ser Otro o por el imaginario de la raza, religión o grupo social, la posibilidad de no pertenecer a los Mismos está latente en cualquier sujeto que abandone temporal o por siempre, su esfera social que lo significa como parte de los Mismos.

Tanto el extranjero, como el que regresa a casa, se encuentra en la intersección entre los Mismos y los Otros, como menciona, respecto al extranjero, Simmel (2012):

“El extranjero nos resulta próximo en la medida en que sentimos que compartimos con él una misma naturaleza nacional, social, profesional o genéricamente humana. Pero también nos resulta distante en la medida en esos mismos rasgos no pertenecen sólo a él y a nosotros sino que son propios de muchas más personas".

De ahí que en la significación del Otro entra en juego algo que va más allá del posible común. Pero también ocurre lo dicho por Todorov, donde el

"sentimiento de pertenecer a las dos culturas a la vez [De ahi que] la defensa del grupo al que se pertenece es siempre un egoísmo colectivo; que las influencias exteriores, lejos de ser fuente de corrupción, son a la vez inevitables y provechosas para la evolución de la cultura; que, de todas formas, más vale vivir en el presente que tratar de resucitar el pasado y, en suma, que no es interesante encerrarse en el culto de los valores nacionales tradicionales" (Todorov, 1998).

Quien ha partido o llega a otro sitio que-no-es-el-suyo, se sale de lo común, el cual, para Nancy (2014): “se nos presenta como emblema partido en dos: por un lado la posibilidad de la comunidad, por el otro la reducción del destino común". En lo común no hay cabida para la 
subjetividad, así como en los Mismos, los fraternos, no hay cabida para el rostro del Otro, por eso lo excluyen. Lo común es el sustento de los Mismos, de ahí que quienes han dejado de pertenecer, se escinden en un aquí-allá y, en ese momento, comienza su experiencia del Otro. Esta visita a la alteridad puede ser por lo tanto dolorosa, pero también creativa pues se abre a lo posible en la misma realidad roma de la frontera. Es una posibilidad de autoconstrucción porque el terreno, aunque árido, posibilidad el enfrentamiento con y en lo Otro, se abre al conflicto, exterior e interior, y por lo tanto da espacio para que lo urgente se manifieste a través de un sentido de emergencia vital y ontológica.

Entonces ¿El sentir que se carece de rostro ante la mirada de los Mismos es parte fundamental de la experiencia del Otro? Posiblemente sí, porque el rostro y, sobre todo los ojos, permiten reconocernos como sujetos, basta pensar en la imagen con la que se suele representar a los bandidos o los superhéroes en la cultura popular, ellos cubren sus ojos o rostro, por lo tanto, la posibilidad de ser identificados. Dejan clara su apariencia como Otro, un Mismo no haría lo que ellos.

\section{E1 rostro del Otro}

La importancia del rostro y los ojos, pues a través de ellos se significa al sujeto, pero también, recuerda la mortalidad, como menciona Levinas:

"Un rostro del otro que -bajo todas las formas particulares de la expresión en las que el otro, ya en la piel de un personaje, representa su papel-es en cuanto tal expresión pura, extradición sin defensa ni disfraz: extrema literalidad y precisión del frente a... que es, en esta desnudez, la exposición a la muerte: desnudez, pasividad y vulnerabilidad pura. El rostro como la mortalidad misma del otro hombre" (Levinas, 2001). 
El Otro a través de su rostro recuerda constantemente la muerte, por eso se le nulifica borrándolo, porque de lo contrario, ocurre que:

"a través del rostro del otro - a través de su mortalidad-, todo aquello que de lo demás no me compete, "tiene que ver conmigo". Respons abilidad respecto de otro: el rostro como queriéndome decir «no matarás" $y$, en consecuencia, también: "eres responsable de la vida de ese otro absolutamente otro", responsabilidad respecto del único. El único, es decir, el amado, siendo el amor la condición de posibilidad misma de ese único" (Levinas, 2001).

El amor se otorga hacia el único, hacia el fraterno, al que forma parte de los Mismos. El Otro al carecer de rostro para los Mismos, los libera de la responsabilidad hacia su persona, el dilema ético solo opera en los que tienen rostro: el-parecido-a-mi. De ahí que la ética, para Levinas, como una responsabilidad hacia los otros, es: relación con los otros, con el prójimo -cuya proximidad no podría confundirse con una cercanía en el sentido espacial-. "Prójimo" subraya, en primer lugar, el carácter contingente de esta relación, porque el otro, el prójimo, es el primero que llega. Dicha relación es una proximidad que constituye una responsabilidad hacia los otros. Responsabilidad obsesiva, responsabilidad que es una obsesión, porque el otro me asedia, hasta el punto de que pone en tela de juicio mi "para mí", mi "en sî", me toma como rehén. Y esta situación incondicional de rehén es la condición sin la cual no se podría jamás decir un sencillo "Detrás de usted, señor». Lo cual quiere decir que, en la crisis actual moral, sólo queda la responsabilidad hacia otros, responsabilidad sin medida, que no se parece a una deuda, de la que siempre se podría absolver, porque, con los demás, no se está nunca absuelto. Esta responsabilidad llega hasta 
la escisión, hasta la desnucleación del yo. Y esa es la subjetividad del yo (Levinas, 2008).

Por lo anterior ¿Ese Prójimo que se vincula con la responsabilidad hacia los otros forma parte de los Mismos? De ser así ¿Es un prójimo como Único? Entonces ¿Al que no se significa de esa forma, sólo se le da por añadidura, por su condición como humano, la responsabilidad hacia otros? ¿El yo como un Mismo frente al tu como Otro? ¿Y si se le interpreta y se le conoce al Otro desde la analogía, cambiará el sentido de responsabilidad hacia una solidaridad ante él? Pues:

"el juicio del saber verdadero y del pensamiento temático se invoca o se inventa a partir o a propósito de ciertas exigencias que derivan de la significación ética del otro, inscrita en su rostro; son imperativos en el rostro del otro que se me revela como incomparable, que es único: hay exigencias que obligan a la concreción de la justicia" (Levinas, 2001).

De ahí que una forma de devolver el rostro al Otro para conocerlo y que lleve al juicio verdadero y el pensamiento temático, podría darse por medio de la analogía. Pero en lugares donde los Mismos definen claramente su diferencia ante los Otros, como las fronteras, se complejiza el asunto.

\section{La solidaridad hacia el Otro}

En la frontera como espacio de conjunción, se puede construir una solidaridad hacia el Otro en lugar de la fraternidad de los Mismos. Por medio de una solidaridad, se puede construir la confianza en el Otro, lo que conlleva a una ética analógica, con la cual, para Beuchot:

"llevará a una vida más equilibrada, pero no con el equilibrio rígido y hasta inalcanzable -por inhumano-de la univocidad; pero tampoco dejará caer en una vida desequilibrada con la desproporción de la 
equivocidad. Será la vida según la proporción, que es lo que los griegos consideraban como la existencia virtuosa, la vida en la virtud. Sin embargo, también se insistirá en el deber, en la carga de obligación que recibe la adquisición y cultivo de ciertas ideas" (Beuchot, 2004b).

Es una ética prudente, mesurada, que podría mediar entre los Mismos y los Otros, entre la frontera como ídolo y como ícono. Un espacio de liberación para la vida donde converjan los Mismos y los Otros. La frontera como espacio para la liberación, es curativo, y acaso llegar a él a través del pensamiento alfa original, como señala Barfield, nos haría ver con mayor claridad por qué esto es así, esa pensamiento prístino señalaría la frontera como espacio más allá de las polaridades pues las integraría y eso la haría potencialmente curativa y creativa en modo sumo. En palabras de Barfield:

"la diferencia más notable entre la figuración primitiva y la nuestra es que la primitiva implica "participación", esto es, una certeza, que nosotros ya no poseemos, de que existe un vínculo extrasensorial entre el percipiente y las representaciones. Esto implica no sólo que nosotros pensamos de modo diferente, sino que los propios fenómenos -las representaciones colectivas-son diferentes" (Barfield, 2015).

Salvada este problema de "pensamiento" y su interrelación con la "visión" de la que parte y a la que se puede abrir, la frontera puede ser repensada, revisionada e incluso redefinida. Esta aceptación de la complejidad es ciertamente analógica y se fundamentan en que los contrarios, aun aceptando su contraposición estructural y sistémica, van hacia una unión superior en la que son ante todo necesarios para la manifestación de la entidad que conforman, un poco como el yin y el yang 
que forman el Tao, su valor es antes integrador que disgregador y así la lucha es más bien un baile que aporta mayor armonía al estado de los contrarios unificados en la realidad que Es, al hilo de las teorias propias que el no dualismo orienta, como es el caso del Advaita Vedanta 3 por ejemplo.

\section{Conclusión}

La propuesta de Dussel de la solidaridad en lugar de fraternidad, permite construir puentes entre los Mismos que son fraternos y los Otros que se les ha borrado el rostro, porque se va más allá de la fraternidad de los comunes, lo que se establece es:

"la relación de solidaridad, que tiene cordialidad con el miserable (misericordia), supera la fraternidad de la a mistad en el sistema [...] y se arriesga a abrirse al ancho campo de la alteridad que se origina por una "responsabilidad por el Otro" preontológica [....] el que se ayude o no al Otro, en el efectuarse empírico de la solidaridad, no evita que ya siempre antes se era responsable por el Otro. El que no lo ayuda traiciona esa responsabilidad preontológica" (Dussel, 2012).

Por medio de la solidaridad no se traiciona la responsabilidad preontológica ante el Otro, esté se significa como Prójimo, pero para ello se requiere una ética ante el Otro analógico, la cual sólo se construye devolviendo su rostro por medio de la analogía. De esta forma, en los lugares cerrados por el constante flujo de sujetos, como la frontera, se podrán abrir y convertirse en íconos que liberen al sujeto de su carga. Una forma de iniciar esa solidaridad ante el otro y devolverle el rostro es

\footnotetext{
3 Nota del Editor: Sánscrito: अद्वैत वेदान्त: Advaita Vedānta, literalmente, "no-dualidad" Noción de sujeto diferente de modelo cartesiano "cuerpo-alma" que se desarrollada en la India principalmente por Mahavira y Buda -si es que existió-, llamado también budismo vajra o tantrico, y que entiende que el sujeto es una construcción de la cultura y en relación a los otros.
} 
por medio del saludo en el sentido de Oriente, pues como menciona Han (2019): “La amabilidad del saludo se basa en el dialogismo del reconocimiento, del dejar-ser empático, del permitir-estar-presente al otro [...] El saludo responde a la mirada del otro". De ahí que al responder la mirada se rompe con las divisiónes de las castas, razas, nacionalidades que marcan tanto las fronteras nacionales como culturales creando un espacio de libertad sustentada en la covergencia. 


\section{Referencias}

Barfield, Owen (2015). Salvar las apariencias. Girona: Atalanta.

Barthes, Roland (2014). El imperio de los signos. Barcelona: Seix Barral.

Beuchot, Mauricio (2004a). Antropología filosófica. Hacia un pe rsonalismo analógicoicónico. España: Fundación Emmanuel Mounier

Beuchot, Mauricio (2004b). Ética. México: Editorial Torres Asociados.

Buber, Martin (1998): Yo y tú, Caparrós, Salamanca

Dussel, Enrique (2012). Pablo de Tarso en la filosofia política actual y otros ensayos. México: Ediciones Paulinas.

Han, Byung-Chul (2019). Ausencia. Acerca de la cultura y filosofía del Lejano Oriente. Argentina: Caja Negra.

Levinas, Emmanuel(2001). Entre nosotros. Ensayos para pensar en otro. España: Pretextos.

Levinas, Emmanuel (2008). Dios, la muerte y el tiempo. España: Cátedra.

Nancy, Jean-Luc (2014). El común el menos común. Metapolítica Año 18, No. 86.

Pániker, Salvador (2001). Aproximación al origen. Barcelona: Kairós.

Pániker, Salvador (2006). Ensayos retroprogresivos. Barcelona: Kairós.

Pániker, Salvador (2016). Asimetrías. Hibridismo y retroprogresión. Barcelona: Kairós.

Simmel, Georg (2012). El extranjero. En: El extranjero. Sociología del extraño. España: Sequitur.

Sen, Amartya (2008). Identidad y violencia. La ilusión del destino. Argentina: Katz Editores.

Todorov, Tzvetan (1998). El hombre desplazado. España: Taurus. 